\title{
Objetividade e subjetividade nas ciências sociais: introdução às relações interdisciplinares entre direito e desenvolvimento
}

\author{
OBJECTIVITY AND SUBJECTIVITY IN SOCIAL \\ SCIENCES: INTRODUCTION TO INTERDISCIPLINARY \\ RELATIONS BETWEEN LAW AND DEVELOPMENT
}

* André Parmo Folloni

Resumo: As relações entre Direito e desenvolvimento pressupõem estudo interdisciplinar no âmbito das ciências sociais. Esse tipo de estudo, porém, precisa lidar com o problema da objetividade, porque sustentar um dever de desenvolvimento pressupõe um juízo de valor. $\mathrm{O}$ artigo apresenta algumas discussões, no âmbito das ciências sociais, a respeito do problema da objetividade ou da subjetividade do conhecimento científico. Trata das distinções entre ciências naturais e ciências sociais mas, também, do fundamento empírico que, embora diferentemente, todas pressupõem. Superado esse ponto, avança-se procurando compreender o que se entende por objetividade científica em oposição à subjetividade, apresentando três significados possíveis: a reificação do objeto de pesquisa, a não valoração por parte do pesquisador e a não intervenção do pesquisador sobre o objeto de estudo. Essas três objetividades são, então, avaliadas de acordo com determinadas visões de ciência social e, em específico, de Ciência do Direito, permitindo as conclusões do artigo, governado pela epistemologia como seu método.

Palavras-chave: Ciências sociais; Epistemologia; Complexidade; Desenvolvimento; Direitos Fundamentais.

* Professor do Programa de Pós-Graduação em Direito (Mestrado e Doutorado) da Pontifícia Universidade $\mathrm{Ca}$ tólica do Paraná. Líder do Grupo de Pesquisas Tributárias do PPGD da PUCPR. Doutor em Direito do Estado pela Universidade Federal do Paraná. e-mail: folloni.andre@pucpr.br

Abstract: The relationship between Law and development require interdisciplinary study in the social sciences. Such studies, however, need to face the problem of objectivity, because a claim for development presupposes a value judgment. The article presents some discussions in the social sciences on the problem of subjectivity or objectivity of scientific knowledge. It studies the distinctions between natural sciences and social sciences but also the empirical basis that, although differently, all of them presuppose. Then the article try to understand what is meant by scientific objectivity as opposed to subjectivity, featuring three possible meanings: the reification of the research object, the non-assessment by the researcher and the non- 
intervention of the researcher on the studied object. These three meanings of objectivity are then evaluated according to certain visions of social science, and in particular, the science of law, allowing the conclusions of the article, ruled by the epistemology as its method.

Keywords: Objectivity; Subjectivity; Law; Development; Social sciences. 


\section{INTRODUÇÃO}

As relações entre Direito e desenvolvimento pressupõem estudo interdisciplinar no âmbito das ciências sociais. E pressupõem, ainda, dois juízos, um de fato e um de valor. É o juízo de fato apontar determinada realidade social como desenvolvida, não desenvolvida ou em desenvolvimento, de acordo com determinado conceito de desenvolvimento. É juízo de valor sustentar que determinada realidade, diante do seu estádio atual, deve buscar estádios superiores de desenvolvimento.

Pensar as relações entre Direito e desenvolvimento demanda, portanto, refletir a respeito da legitimidade de juízos de valor no âmbito das ciências - em particular, das ciências sociais. Isso leva ao problema da subjetividade ou objetividade científicas. Este artigo tem a pretensão humilde de apontar algumas das questões principais que se apresentam no discurso epistemológico das ciências sociais quando o assunto é objetividade científica.

No primeiro item, o artigo reflete a respeito das distinções entre ciências naturais e ciências sociais e do que elas podem ou devem apresentar em comum. Em seguida, nos três pontos seguintes, busca-se compreender o que se pode entender por objetividade científica em oposição à subjetividade. Três formas de compreender "objetividade científica" são apresentadas: a reificação do objeto de pesquisa, a não valoração por parte do pesquisador e a não intervenção do pesquisador sobre o objeto de estudo. Essas três objetividades são, então, avaliadas de acordo com determinadas visões de ciência social e, em específico, de Ciência do Direito.

\section{O DUALISMO METODOLÓGICO ENTRE CIÊNCIAS NATURAIS E CIÊNCIAS SOCIAIS}

Quando se debate acerca do problema da objetividade e da subjetividade nas ciências sociais, um dos assuntos que comumente surgem é a diferença de estatuto epistemológico entre elas e as ciências naturais. A questão da objetividade, então, deveria ser vista diferentemente no âmbito das ciências da natureza e no âmbito das ciências sociais - também chamadas "ciências do homem" ou "ciências do espírito" (Geisteswissenschaften, na famosa elaboração de WILHELM DILTHEY). 
O neopositivismo do início do Século XX encontrou uma unidade metodológica entre as ciências sociais e as ciências da natureza. NORBERTO BOBBIO, por exemplo, explica que "...um dos traços mais característicos da epistemologia neopositivista..." é “...a consideração unitária das ciências, que implica a não-distinção entre ciências naturais e ciências sociais ou humanas" (2006, p. 173). A unidade estaria no empirismo. Isso significa que, para os empiristas lógicos, tanto as ciências humanas, quanto as ciências da natureza, precisariam referir suas proposições explicativas a uma realidade suscetível de apreciação pela experiência. Nesse modelo, para que um saber qualquer, inclusive se voltado às questões sociais ou culturais, possa alcançar o status de "verdadeira ciência", deve ser empírico - como anota, ainda, BOBBIO: "Para serem consideradas ciências, as ciências sociais devem tornar-se ciências empíricas, seguindo o exemplo das mais avançadas ciências naturais" (2006, p. 173).

Em orientação contrária, a Epistemologia das ciências sociais de fundamentação marxista, segundo BOBBIO, prega a distinção entre os métodos de uma e de outra:

Sobre esse tema, a orientação da epistemologia marxista é diametralmente oposta: tende a distinguir as ciências sociais das ciências naturais, a rejeitar a aplicação sic et simpliciter dos métodos e dos procedimentos próprios das ciências naturais às ciências sociais, as quais têm que lidar com o mundo histórico, que é um produto do homem (2006, p. 173).

O fundamento para essa distinção, que BOBBIO exemplifica mediante o recurso a THEODOR WIESENGRUND-ADORNO, baseia-se na verificação de que o sujeito da pesquisa, nas ciências sociais, confunde-se com seu objeto: o ser humano é, enquanto pesquisador, um membro da sociedade que nela ocupa um determinado lugar e é, nesse sentido, também seu próprio objeto de estudo (2006, p. 174). Assim, a separação entre sujeito e objeto, possível nas ciências da natureza, seria inviável nas ciências sociais.

É importante levantar esses temas. Na situação atual em que se encontra a humanidade, os seres humanos, em boa medida, são capazes de controlar a natureza. No entanto, são incapazes de conviver de forma pacífica e respeitosa com seus semelhantes. NORBERT ELIAS credita essa situação à notável evolução do conhecimento das coisas da natureza e das ciências naturais em contraste com as ciências do humano. Isso, inclusive, no que respeita aos 
investimentos empresariais e universitários. Essa “...singularíssima cisão do saber...", diz, é “...altamente caracterizadora da actual situação dos homens nas sociedades mais desenvolvidas" [sic] (1985, p. 27).

Evitando o dualismo maniqueísta, que defende ora a concepção neopositivista, ora a marxista, parece razoável dizer que um mínimo de fundamento empírico todo estudo científico deve ter, sob pena de restar inverificável ou infalseável e, no limite, idêntico ao meramente opinativo. Uma base empírica parece necessária a qualquer estudo científico que deseje se impor por seus próprios méritos como relativamente verdadeiro, ao menos mais próximo de uma verdade objetiva. A coerência interna do discurso científico é tão importante quanto a sua verificabilidade ou falseabilidade empírica - além da adequação pragmática de seus efeitos sociais. Nesse sentido específico e mínimo, toda ciência será empírica.

Nesse sentido trabalha, por exemplo, JOSÉ SOUTO MAIOR BORGES. Logo no início do seu primeiro trabalho de crítica epistemológica no Direito, o autor trata da unidade do método como um postulado teórico - baseado, nesse ponto, em KARL POPPER. Enuncia como “...ponto de partida a unidade metodológica das ciências naturais e das ciências sociais...” (1999, p. 19). Esse ponto de partida terá duas consequências relevantes para aquela obra. Delas, apenas uma é pertinente neste momento: ele concede à Ciência do Direito um critério para a testabilidade empírica de suas afirmações, para que suas "verdades" possam adquirir validade intersubjetiva na comunidade científica. A outra é a interdição da indução enquanto método científico válido. Ambas possibilitam, em conjunto, fundamento à tese principal daquela obra: "...é impossível demonstrar indutivamente um enunciado universal sobre normas, tais como o de que toda obrigação é patrimonial" (1999, p. 23).

Dez anos depois, o mesmo autor retorna ao assunto, tratando do tema da demarcação do conhecimento jurídico com a mesma preocupação fundamental: permitir o controle das proposições científicas no âmbito jurídico. Isso está bem claro: "Sob o ponto de vista da ciência dogmática do Direito, não há suporte para indagações meta-empíricas precisamente porque, nesse campo, não há como refutá-las ou corroborá-las mediante testes experimentais severos" (1994, p. 106). É por essa falta de controle que as proposições sobre um determinado objeto não escoradas empiricamente carecem de cientificidade - como explica SOUTO a respeito do éter estacionário, que é “....insusceptível de corroboração experimental (o que, subtraindo-lhe o caráter empírico, lhe retiraria até a sua cientificidade)" (1994, p. 109). Assim, a unidade metodológica entre as ciências 
sociais, inclusive o Direito, e as ciências naturais, a que alude JOSÉ SOUTO MAIOR BORGES, remete à necessidade de controle intersubjetivo tanto das proposições científico-naturais como das proposições científico-sociais. Nesse sentido, são idênticas as ciências: todas demandam uma instância de controle da veracidade ou da validade das proposições que emitem.

Deve-se, portanto, reconhecer a necessidade de uma instância de teste de verificação ou falseamento às proposições científicas, sejam elas da ciência natural ou da ciência social. Esse teste, para JOSÉ SOUTO MAIOR BORGES, só será possível se houver um fundamento primeiro do qual parta a afirmação e ao qual essa afirmação possa ser contraposta: o fato empírico. A necessidade da testabilidade empírica torna-se, assim, ponto comum nas ciências naturais e nas ciências sociais. Sob esse ponto de vista, a unidade metodológica é um imperativo. $\mathrm{O}$ que não equivale, contudo, a sustentar que todos os métodos praticados em cada uma das ciências naturais apliquem-se indiscriminada a todas as demais ciências naturais, ou a todas e a cada uma das ciências sociais. Nem a defender que o fundamento empírico possa servir, ao mesmo tempo, como fundamento primeiro e como fundamento último. As ciências são diferentes entre si, de acordo com suas necessidades. Mas têm, em comum, a necessidade de um critério para que suas afirmações sejam testáveis enquanto verdadeiras ou falsas. Esse critério é encontrado na empiricidade.

Na Ciência do Direito, essa questão se resolve, na visão de JOSÉ SOUTO MAIOR BORGES, assumindo-se, como ponto de partida, o conjunto de textos de Direito positivo concreto, histórico, determinado e determinante de uma realidade concreta na qual se insere o cientista, e nos quais - Direito positivo e condicionantes históricas que o cercam - ele deve buscar fundamento. Nesse sentido é muito importante prestar atenção a argumentações como a seguinte, de MISABEL ABREU MACHADO DERZI: "Não pode prevalecer, nas circunstâncias históricas atuais, interpretação autoritária, não só contrária à letra da Constituição, como anacrônica, própria de período revolucionário ultrapassado" (1988, p. 140). É dizer: não se interpreta de forma adequada o direito posto sem que se compreenda hermeneuticamente as circunstâncias históricas que o engendram e às quais ele retorna, recursiva e dialeticamente, também as construindo.

Tanto o direito posto quanto sua historicidade concreta são, ontologicamente, dados empíricos objetivos comuns a qualquer cientista do Direito. Passíveis de controle intersubjetivo, portanto. Fixa-se, então, esse primeiro fundamento comum a todos os juristas que trabalham diante da mesma 
realidade espaço-temporal - fundamento capaz, por isso mesmo, de permitir o teste intersubjetivo. Mas a fundamentação da compreensão exata do que significa o Direito positivo dentro da historicidade que o determina e à qual ele também determina, eventualmente aliado a sua aplicação a um caso concreto, isso já é questão intersubjetiva, e o fundamento último da discussão será sempre pragmático.

Por tudo isso, não se pode dizer que o fundamento empírico resolva todos os problemas, nem que a experiência será sempre a mesma em qualquer ciência. Da consideração da relevância científica do confronto empírico para toda ciência não segue que todas as ciências empíricas sejam idênticas. Se o recurso ao empírico dá a fundamentação primeira da teoria, sua fundamentação última, acaso viável, não será jamais empírica. Ela só o poderá ser enquanto fundamentação pragmática. Assim, por um lado, o caráter empírico, entendido no sentido aqui exposto, permite, em alguma medida, o controle ou verificação; por outro lado, tendo em comum o fundamento empírico, há boa dose de diferença entre as ciências naturais e as ciências sociais, bem como entre as diversas ciências naturais e as múltiplas ciências sociais entre si. E, também, entre as várias visões que a Ciência do Direito pode admitir sem perder de vista algum empirismo.

\section{OBJETIVIDADE: A COISIFICAÇÃO DO OBJETO DA PESQUISA}

Embora semelhantes no recurso à prova empírica, as muitas ciências podem ser bastante diferentes. A distinção comum entre ciências naturais e ciências sociais leva à questão da objetividade. É importante fazer uma diferenciação conceitual de duas objetividades: uma significa tratar o objeto do estudo como um objeto mesmo. Seria, no âmbito das ciências sociais, tratar a sociedade como uma coisa, o homem como um objeto. Outra remete à consideração segundo a qual o estudo científico deve depender mais do seu objeto do que do seu sujeito; isto é, o conhecimento depende do objeto estudado e não do estudioso. O estudioso não deve interferir na produção do conhecimento, que deve advir do objeto apenas. Neste ponto será tratada a primeira objetividade e, em seguida, o seu segundo aspecto.

Uma reflexão de THEODOR ADORNO é, aqui, interessante e pertinente. Na época em que escreveu (1957), o sociólogo de Frankfurt nota uma tendência de conceder primazia à sociologia empírica. Contudo, para ele, 
a superioridade dos procedimentos empíricos não é algo óbvio. Porque ainda que objetivo o método, nas ciências sociais o objeto é sempre uma formação a partir de subjetividades: "En general, la objetividad de la investigación empírica es una objetividad de los métodos, no de lo investigado" (2001, p. 22). Nessa sociologia empírica, por exemplo, fazem-se pesquisas que levam em conta o que pensam os entrevistados, mas não aquilo que lhes condiciona as respostas; e, ainda que as respostas reflitam, em certa medida, esses questionamentos - a "objetividade social" -, isso se dá de forma apenas muito incompleta e deformada. Assim, para ADORNO, o método é insuficiente e não penetra a coisa mesma. As questões de método acabam adquirindo importância maior do que a o objeto a ser estudado. E jamais se saberá se a violência metodológica que sofre o labor científico garante o trabalho com qualidade. Além disso, uma metodologia castradora acaba por impedir o avanço em outros temas que poderiam ser relevantes:

Se pretende investigar un tema con un instrumento de investigación cuja propia formulación decide qué es lo que hay que investigar: un círculo vicioso. El gesto de honestidad científica, que se niega a trabajar con conceptos que no sean claros y distintos, se convierte en pretexto para dejar de lado lo investigado en favor de una actividad investigadora autosuficiente (2001, p. 24).

O paradoxo chama atenção: "Pero la razón que adopta como ideal de conocimiento la ley social de corte matemático es, en tal objetividad, razón subjetiva..." (2001, p. 42). Nessa linha, veja-se que objeto de conhecimento adquire, em certas visões do Direito, o status ontológico - e não apenas metodológico - de um corpo de linguagem prescritiva, dirigido às condutas humanas intersubjetiva. O conhecimento, por sua vez, também é um corpo de linguagem, voltado para o outro corpo de linguagem, o Direito positivo. Uma metalinguagem que descreve uma linguagem prescritiva. Não há onde incluir, nesse esquema "Direito positivo - Ciência do Direito", o ser humano. Essa visão reducionista não tem nada a dizer do ser humano duplamente afetado por essas linguagens, delas sujeito e delas objeto.

Segundo ADORNO, o impedimento para transferir à sociedade o modelo das ciências sociais está na sociedade mesma. Tratar, metodologicamente, os seres humanos como objetos, reificando-os, pode levar à impressão ou à compreensão segundo a qual essa objetização é natural e eterna. Exemplo do próprio frankfurtiano: quem pesquisa perguntando a outrem sua preferência 
entre música clássica ou popular, toma como verdadeira a classificação "música clássica/música popular". Pior, ela é tomada como um a priori óbvio e inquestionável. A própria pesquisa já induz a resposta, ou pelo menos afeta sua espontaneidade. A pesquisa reduz a complexidade e a multiplicidade do real a duas alternativas excludentes. A reação do sujeito à música, que é o que deveria ser pesquisado, já está subentendida na pergunta. Já foi definida e paralisada no tempo; em outras palavras, coisificada. Qualidade e quantidade estão no objeto, e uma pesquisa apenas quantitativa ou apenas qualitativa violenta o objeto de estudo (2001, p. 42).

Em adição, diz ADORNO que a necessidade de objetividade nas ciências sociais impõe uma tendência à observação dos individuais como se fossem objetos idênticos, admitindo-se o universal, equivocadamente, como a soma dos individuais. $\mathrm{E}$ isso tendo ainda como outro efeito colateral indesejado o desconhecimento acerca da estrutura condicionante da subjetividade:

Dado que el mecanismo objetivo de la sociedad es imposible de captar adecuadamente en los comportamientos subjetivos aislados, se otorga la máxima objetividad científica a lo general extraído por abstracción del universo de los comportamientos subjetivos, y la objetividad social misma, que no sólo determina los comportamientos subjetivos, sino también los planteamientos científicos, es difamada como superstición (2001, p. 38).

Com isso, ADORNO faz uma crítica importante ao método de redução de complexidades nas ciências sociais. Mesmo em relação às ciências naturais esse imperativo vem sendo questionado. Mas nas ciências sociais, esse questionamento é já está mais bem desenvolvido, uma vez que é mais antigo. Diz ADORNO, em um período no qual o questionamento ainda não havia chegado às ciências naturais: "En las ciencias sociales, a diferencia de lo que ocurre en las ciencias naturales, no puede avanzarse desde la parte al todo, pues en ellas el momento conceptual del todo tiene una lógica que nada tiene que ver con la unidad de notas común a los elementos particulares..." (2001, p. 31). Para ele, pretender investigar os fatos individuais para, em seguida, obter o conhecimento do todo social, é um equívoco metodológico que leva a resultados equivocados. Porque os membros da sociedade são largamente diferentes uns dos outros - não são objetos fordianamente produzidos em série - e generalizar seu comportamento sempre implicará a perda dessa diversidade. No direito, diríamos: não existe $o$ juiz; existem juízes, muitos e muitos deles, 
cada um mais ou menos diferente de todos os outros, e sujeitos aos mais variados tipos de determinações.

\section{OBJETIVIDADE: O OBJETO OBSERVADO CONTRAPOSTO AO SUJEITO OBSERVADOR}

Outra das distinções que expõe NORBERTO BOBBIO é bastante forte: o objeto das ciências naturais, em larga medida, independe da atuação do homem, diferentemente do objeto das ciências sociais, que depende da atuação do homem - inclusive, em maior ou menor medida, do cientista. Imagine-se a cosmologia: deixar de atribuir a condição de planeta a Plutão em nada modifica sua ontologia. Nas ciências sociais, essa independência, se existe, é em muito menor medida. Deixar de definir uma aspecto do Direito como "jurídico" pode interferir fortemente em sua constituição ontológica. Uma parte do Direito deixa de ser Direito. Se a realidade socioeconômica e o desenvolvimento são, por um expediente metodológico, excluídos do Direito, reduzido este a um conjunto de normas, sua pesquisa fica, desde logo, interditada aos juristas e, eventualmente até, à atuação do Poder Judiciário - que passa a ser acusado de aceitar argumentos políticos e econômicos quando seu julgamento deveria ser jurídico. Mas o que é jurídico? O que assim for definido pela teoria jurídica. O expediente metodológico conforma e transforma, então, o objeto.

Ainda que se argumente que não há distinção qualitativa, mas apenas quantitativa, haverá de qualquer forma distinção. A sociedade pode ser alterada pela evolução das ciências sociais; já Plutão não mudará, ao menos não tão cedo, pela evolução das ciências naturais - ainda que a ciência, inclusive a natural, tenha uma confiança fantástica em suas possibilidades e uma impossibilidade é sempre uma "ainda" impossibilidade, como lembra FRANZ J. HINKELAMMERT.

A imortalidade do homem é impossível, mas é possível em princípio a partir do progresso infinito da ciência médica (Popper). Viajar por telefone é impossível, mas torna-se possível em princípio a partir do progresso infinito da cibernética (Norbert Wiener). A concorrência perfeita é impossível, mas torna-se possível em princípio pela tendência ao equilíbrio do progresso infinito. Com sua ilusão da concorrência de proprietários privados prescindindo de qualquer Estado, o anarco-capitalismo é impossível, mas, à luz do progresso infinito, transforma-se em possível 
em princípio (Hans Albert). É impossível saber tudo, mas isso torna-se possível em princípio à luz do progresso infinito (Einstein). E o mesmo vale para toda a ciência empírica e para todas as impossibilidades negadas pelos princípios de impossibilidade que estão em sua origem, tanto histórica como logicamente. Toda esperança humana deriva da interrelação social e é projetada no sentido da infinitude do progresso técnico, à luz da qual torna-se possível em princípio. A idéia de que ninguém vá precisar trabalhar mais torna-se possível em princípio, bem como a idéia de que as máquinas pensarão por nós também se torna possível em princípio (1988, p. 215).

No mesmo sentido, ADORNO diz que o objeto das ciências sociais é “...un campo de tensión de lo posible y lo real: éstos, simplemente para poder ser, se necesitan el uno al otro" (2001, p. 20).

Assim, se acima foi feita uma crítica à objetividade no sentido de entender o objeto de estudo como um objeto mesmo, no sentido de uma coisa, como uma pedra ou um planeta, agora faz-se uma crítica à objetividade no sentido de entender que a ciência social independe do sujeito que a realiza, mas apenas do objeto sobre o qual esse sujeito se volta. Objetivo em razão de suposta independência do objeto em relação ao sujeito do estudo, não objetivo no sentido de o objeto de estudo ser um objeto. Objetivo, agora, é o conhecimento que independe das inclinações ou da influência do sujeito que conhece.

Nota-se o motivo pelo qual esse problema atormenta tanto as ciências sociais, e porque é tão pouco, ao menos tradicionalmente, enfrentado nas ciências naturais: não faz sentido julgar se a órbita terrestre será melhor se for elíptica ou circular, porque não é possível, atualmente, alterá-la. Ao contrário, faz todo sentido julgar se a Economia será melhor se houver ampla liberdade mercado ou, diferentemente, se o Estado exercer sobre ela controle intenso: porque a liberdade de mercado - ou o controle estatal dependem de decisão humana, que pode ser tomada, num sentido ou no outro, influenciada pela pesquisa teórica. Isso leva à distinção entre ciências normativas e ciências positivas, tão presente na Economia: normativa é a ciência que pretende dizer como a realidade deve ser para que seja melhor do que é, fundada numa avaliação axiológica; positiva é a ciência que pretende dizer como a realidade é (FOLLONI, 2013, p. 407). Se esta última, em vários campos das ciências naturais, é a única que faz sentido, a primeira sempre faz sentido nas ciências sociais. 


\section{VALORAÇÃO}

Em sentido diverso, a objetividade pode ser compreendida como a ciência feita sem a valoração do cientista. Em relação a esse problema, é possível diferenciar duas questões: se essa inexistência de apreciação valorativa, por um lado, é possível no âmbito das ciências sociais; Por outro lado, se essa ausência de valoração, caso possível, seria desejável. No primeiro caso, a resposta é produzida na forma de um juízo de fato; no segundo, de um juízo de valor.

Uma primeira discussão é se a objetividade, tomada nesse sentido, é possível. Diz BOBBIO que alguns consideram essa via não valorativa impossível, porque, “...diferentemente do físico, do químico ou do biólogo, o sociólogo, o economista e o cientista político participam emocionalmente, isto é, com toda a 'faculdade de desejar', nos eventuais resultados de suas pesquisas..." (2006, p. 176). A consideração segundo a qual o objeto das ciências sociais é um eterno devir e alterável pela ação humana, e, portanto, pela ação do cientista, é o que leva, então, a que se considere impossível a objetividade nas ciências sociais na forma como ela é viável nas ciências naturais. Para essa linha argumentativa, o cientista social está muito mais envolvido com seu objeto de estudo do que o cientista natural. Seu interesse na pesquisa impediria uma objetividade absoluta, porque ele sempre tenderia a valorar seu objeto, na intenção de alterá-lo.

Quem prega esse tipo de objetividade à ciência social prega a não valoração. Explica NORBERTO BOBBIO, em linguagem que beira a ironia, dado o "contragosto" que enfrenta ao tratar do tema:

Pode-se compreender que se as ciências sociais pretendem ser ciências somente quando seguem os passos das ciências naturais, quando imitam em tudo as ciências que estudam em laboratório, com instrumentos de precisão que tendem a eliminar toda intervenção do sujeito que conhece, um objeto moral ou politicamente indiferente como podem ser um protozoário ou um fio de grama, elas devem considerar a absoluta abstinência de juízos de valor como um requisito da sua cientificidade (2006, p. 175).

Segue o mestre italiano:

Em suma, para quem... acredita que o único modo de fazer do saber sociológico, uma forma de saber cientifico, seja o de aplicar também a ele os 
métodos mais avançados das ciências da natureza, o cientista social deve assumir diante do próprio objeto a mesma postura de neutralidade ou de indiferença que assume o astrônomo diante das estrelas, ou o entomólogo diante do formigueiro (2006, p. 176).

A indiferença, o desinteresse, são categorias psicológicas. Diríamos que se houvesse desinteresse e indiferença completos não haveria ciência: o cientista só faz ciência porque se interessa pela ciência, seja qual for o motivo desse interesse. RENATO MEZAN, por exemplo, cogita duma leitura psicanalítica da teoria científica em busca da influência que nela exercem os caracteres da personalidade do autor (2002, p. 324).

Mas valorar o objeto é diferente: é fazer um juízo de valor, isto é, dizer se o objeto é bom ou mal, se é justo ou injusto, se é bonito ou feio etc. Não valorar não significa manter-se indiferente e desinteressado. Talvez por isso JOSÉ SOUTO MAIOR BORGES use aspas ao falar do desinteresse do cientista, quando se refere à “...pura e 'desinteressada' construção doutrinária” (1994, p. 107). Em tese, é possível que o cientista possa descrever um objeto sem julgá-lo. Quem afirma que os impostos, no Brasil, sempre que isso for possível, devem ser graduados segundo a capacidade econômica do contribuinte, embora utilize a forma "dever-ser", não necessariamente valora ou julga nada, se o fundamento pelo qual diz que as coisas devem ser dessa forma é o art. $145, \S 1 .^{\circ}$ da Constituição da República ${ }^{1}$. Veja-se, em uma exemplificação quase desnecessária e próxima de um truísmo, mas útil apenas para não deixar a afirmação sem qualquer confirmação empírica, a doutrina de ROQUE ANTONIO CARRAZZA: "É por isso que, em nosso sistema jurídico, todos os impostos, em princípio, devem ser progressivos" (1999, p. 65). Esse dever-ser de que o autor se vale nesta passagem nada julga; descreve, explica o que está prescrito no ordenamento. HANS KELSEN explicou esse dever-ser descritivo e não valorativo característico da ciência jurídica dogmática: “Os enunciados de dever ser nos quais o teórico do Direito expõe as normas têm uma significação meramente descritiva; eles, reproduzem descritivamente o 'dever ser' das normas" (2000, p. 237).

${ }^{1} \mathrm{CF}$, art. $145, \S 1 .^{\circ}$. "Sempre que possível, os impostos terão caráter pessoal e serão graduados segundo a capacidade econômica do contribuinte, facultado à administração tributária, especialmente para conferir efetividade a esses objetivos, identificar, respeitados os direitos individuais e nos termos da lei, o patrimônio, os rendimentos e as atividades econômicas do contribuinte". 
Se isso, no entanto, implica apenas uma autoimposição de não valoração ou se encobre uma ideologia conservadora é outro problema - como no imobilismo teórico do direito tributário brasileiro denunciado por JOSÉ SOUTO MAIOR BORGES: "Sob pretexto de corresponderem à quinta-essência da inovação e modernização dos estudos jurídicos, tendem, essas doutrinas, a um entrincheiramento teórico que mal dissimula seu caráter de ideologia conservadora" (1999, p. 104). O que SOUTO quer dizer aqui é que a defesa do método sempre igual traduz uma ideologia acadêmica conservadora. Eé possível a isso adicionar reflexões como a de RENATO MEZAN:

Freud está muito bem instalado nas suas identificações, pois é um cientista. Dentro da cultura, ele escolheu aquilo que é a garantia de impessoalidade, de objetividade máxima, e certamente a sua insistência em que a psicanálise é uma ciência tem uma das suas raízes nesse fato (2002, p. 351).

Ser um racional e asséptico cientista pode ser o subterfúgio para fugir ao juízo de valor ou para escondê-lo. Mas descrever sem julgar é possível. E, a depender da espécie de trabalho que se está a realizar, necessário. MICHAEL LÖWY lembra:

Se alguém recebe dinheiro para escrever um artigo provando, por exemplo, que o esgoto de São Paulo é o melhor do hemisfério ocidental, seu trabalho não vai ter nada a ver com um trabalho científico. Isso porque ele já partiu da hipótese de que o objetivo dele não era conhecer a verdade, mas fazer propaganda para, suponhamos, o departamento de esgotos do Estado (1989, p. 45).

Isso não significa, contudo, que toda honestidade científica é impossível, como reconhece o mesmo autor: "Mas o que é importante no terreno das ciências sociais é aquela ciência que resulta efetivamente de uma tentativa sincera de produzir um conhecimento científico" (1989, p. 45). Assim, na psicanálise, e por exemplo, RENATO MEZAN:

Também se precisa perguntar onde estão os equívocos eventuais da interpretação que estamos propondo e quanto de nós mesmos, projetivamente, não está intervindo nisso, ou seja, quanto daquilo que estamos pensando sobre o objeto em questão não se deve à nossa contratransferência, apressadamente hipostasiada em interpretação. Se tomarmos esses cuidados elementares, freqüentemente os resultados serão muito interessantes (2002, p. 320). 
Mas outro problema se insinua quando pensamos se, pressuposto como possível, esse caminho não valorativo é desejável. É o que expõe NORBERTO BOBBIO: alguns cientistas sociais de contornos marxistas

...consideram que a não valoração, ainda que fosse possível, não seria desejável, porque esteriliza a pesquisa e deforma o papel do pesquisador, que não é somente o de contemplar a sociedade, mas também o de intervir para modificá-la (e para intervir são necessárias tomadas de posição que orientem a pesquisa mais em uma direção que em outra) (2006, p. 176).

Para ADORNO - exemplo referido por BOBBIO de pensador na linha marxista - essa objetividade não é desejável. É que o afã por dizer exatamente o que se passa e apenas o que se passa acaba por se colocar, intencionalmente ou não, a serviço do que se passa. Converte-se em ideologia, que se liga a uma atitude conservadora. Disso, o sociólogo de Frankfurt conclui que, nas ciências sociais, a validade da experiência aumenta com a participação subjetiva do sujeito cognoscente, e não o contrário. A inspiração do cientista é fundamental. Nada de integrar-se em uma comunidade científica tolhendo-se a criatividade. Nada de ver essa criatividade como um fator perturbador. A intuição deve ser ressaltada e não sufocada. Daí sua crítica: "La idea de que un investigador necesitaría un $10 \%$ de inspiración y un $90 \%$ de transpiración, que tanto gusta de citarse, es servil y su objetivo es prohibir el pensamiento" (2001, p. 32-33). Diz, ainda, ADORNO:

...la falta de espíritu no solamente se celebra como virtud de quien se integra modesta y armoniosamente en un team, sino que además se institucionaliza normando el curso de la investigación, que apenas conoce ya la espontaneidad del individuo más que como factor perturbador. Pero la antítesis entre sublime inspiración y concienzudo trabajo de investigación es absurda (2001, p. 33).

Acerta NORBERTO BOBBIO quando diz que a desejabilidade da valoração depende da concepção do papel do cientista. Depende de saber o que o cientista deve fazer: valorar para modificar, de um lado, ou não valorar, de outro - seja essa não valoração feita no sentido de manter o existente, seja, bem diferentemente, por entender que valorar não é o seu papel.

Sobre esse ponto, duas coisas podem ser ditas: em primeiro lugar, valorar não é incompatível com fazer ciência. Quem não admite o valorar como algo 
compatível ao proceder científico pressupõe um conceito de ciência tão estrito que não cabe mais nem no âmbito das ciências naturais - que constantemente valoram e, entendendo que um bem natural seria melhor se fosse diferente, movimentam-se para modificá-lo. E quem disser que isso foge do âmbito da ciência terá o ônus de sustentar que um alimento transgênico ou um remédio para a garganta não são frutos da atividade científica. Ou entender que o cientista, quando considerou que seria melhor se o tomate fosse de outra forma, ou que valorou como positiva a vida com saúde em relação à vida em doença, não agiu em nome da ciência. É que, além de valorar, o cientista deverá ter tomado uma decisão.

Quem argumenta nessa linha fatalmente terá, para fundamentar essas considerações, que chegar ao conhecido e tradicional argumento segundo o qual decisões são sempre irracionais e jamais fruto de cognição, e por isso jamais podem ser tomadas em nome da ciência. Porém, entender que o papel do cientista não é valorar porque a valoração, por definição, está fora do âmbito da ciência, já que é sempre volitiva e nunca racional, é pura e simplesmente cometer um equívoco. O juízo, lembra ERNST CASSIRER, “...el poder central del hombre, la fuente común de la verdad y de la moral..." na tradição grega, é obtido por diálogo, e diálogo racional, segundo "...el pensamiento de Sócrates... que define al hombre como aquel ser que, si se le hace una pregunta racional, puede dar una respuesta racional (1974, p. 26). Numa visão estreita de ciência, nada disso seria racional. Porque, equivocadamente, entende-se a valoração como sempre irracional. Mas a ciência, seja qual for, pode valorar, e muitas vezes o faz.

Em segundo lugar, saber se o cientista deve valorar para influir no objeto em vistas a modificá-lo é uma questão ética e, nessa qualidade, em certo sentido, anterior às considerações propriamente científicas. Depende do papel que se entende deva, o cientista, assumir perante a sociedade na qual se insere: deve procurar ser um observador imparcial ou deve valorar a realidade e, com base nessa valoração, orientar sua conduta. O problema é claramente ético, deontológico. Observar para interferir ou observar sem interferir é fruto de uma tomada de decisão, não isolada e nem mesmo necessariamente irracional. Mas, nesse caso, certamente ética. Aqui se defende que a atuação do cientista deve ser comprometida com o aprimoramento da vida humana concreta de cada sujeito e, por isso, com o desenvolvimento, no sentido de aumento das liberdades de cada um (SEN, 2000, p. 10-32). 


\section{CONSIDERAÇÕES FINAIS}

Diante do exposto, algumas conclusões podem ser, topicamente, enumeradas:

1. As várias ciências são diferentes entre si, e dependem de critérios diversos de validação e de verificação de suas proposições explicativas ou normativas.

2. Entre as ciências naturais e as ciências sociais, uma das distinções apontadas pelo pensamento epistemológico tradicional é a questão do sujeito cognoscitivo: nas ciências naturais, em muitos casos, o observador é externo ao sistema observado, e, embora esteja suscetível às questões interpretativas, nele não interfere com sua observação; nas ciências sociais, o observador é interno ao sistema observado.

3. Mesmo diante das diferenças, há certo consenso na epistemologia contemporânea a respeito da necessidade de uma instância de validação empírica dos argumentos criados pelo saber científico.

4. No Direito, essa instância empírica é formada pelo ordenamento jurídico a ser examinado e pela realidade histórico-cultural em que esse ordenamento se insere.

5. A demanda de objetividade no conhecimento científico admite vários significados.

6. Um dos significados é o tratamento do objeto de investigação como um objeto, uma coisa: a reificação do objeto de conhecimento. Embora esse seja um expediente possível em várias ciências naturais (geologia, por exemplo), é inviável nas ciências sociais.

7. Outro significado é a possibilidade de interferência do sujeito sobre o objeto observado. Embora essa possibilidade não exista em algumas ciências naturais (astronomia, por exemplo), apresenta-se nas ciências sociais, na medida em que a interpretação co-constitui o objeto interpretado.

8. Outro significado, ainda, liga-se à noção de objetividade enquanto desinteresse, ou ausência de valoração, entre o cientista e o objeto de estudo. Embora essa ausência de valoração seja possível em tese, é de se admitir que, naquelas ciências nas quais o objeto pode ser alterado pela atuação do sujeito cognoscitivo, a valoração possa existir e possa fundamentar uma tomada de ação do sujeito, baseada em um juízo de valor. Essa é uma questão ética. 


\section{REFERÊNCIAS}

ADORNO, Theodor. Epistemología y ciencias sociales. Valencia: Frónesis, 2001.

BOBBIO, Norberto. Nem com Marx, nem contra Marx. Trad. Marco Aurélio Nogueira. São Paulo: Unesp, 2006.

BORGES, José Souto Maior. Ciência feliz: sobre o mundo jurídico e outros mundos. Recife: Fundação de Cultura Cidade do Recife, 1994.

. Obrigação tributária: uma introdução metodológica. 2. ed. São Paulo: Malheiros, 1999.

CARRAZZA, Roque Antonio. Curso de direito constitucional tributário. 12. ed. São Paulo: Saraiva, 1999.

CASSIRER, Ernst. Antropología filosófica: introducción a una filosofía de la cultura. Trad. Eugenio Imaz. México: Fondo de Cultura Económica, 1974.

DERZI, Misabel Abreu Machado. Medidas provisórias: sua absoluta inadequação à instituição e majoração de tributos. Revista de direito tributário. São Paulo, n. 45, jul./set., 1988.

ELIAS, Norbert. Condição humana: considerações sobre a evolução da humanidade, por ocasião do quadragésimo aniversário do fim de uma guerra (8 de maio de 1985). Trad. Manuel Loureiro. Lisboa: Difel, 1985[?].

FOLLONI, André. Ciência do direito tributário no Brasil: crítica e perspectivas a partir de José Souto Maior Borges. São Paulo: Saraiva, 2013.

HINKELAMMERT, Franz. Crítica à razão utópica. Trad. Álvaro Cunha. São Paulo: Paulinas, 1988.

KELSEN, Hans. Teoria geral do direito e do estado. 3. ed. 2. tir. Trad. Luís Carlos Borges. São Paulo: Martins Fontes, 2000. 
LÖWY, Michael. Ideologias e ciência social: elementos para uma análise marxista. São Paulo: Cortez, 1989.

MEZAN, Renato. Interfaces da psicanálise. São Paulo: Companhia das Letras, 2002.

SEN, Amartya. Desenvolvimento como liberdade. Tradução de Laura Teixeira Motta. São Paulo: Companhia das Letras, 2000.

Artigo recebido em: 22/09/2014 Aprovado para publicação em: 22/10/2014

Como citar: FOLLONI, André Parmo. Objetividade e subjetividade nas Ciências Sociais: introdução às relações interdisciplinares entre Direito e desenvolvimento. Revista do Direito Público. Londrina, v.9, n.3, p.25-43, set./dez.2014. DOI: 10.5433/1980-511X.2014v9n3p25. 